Physics and Chemistry of Minerals

https://doi.org/10.1007/s00269-018-1015-5

Revision_1

7

\section{H-bonding in lazulite: A single-crystal neutron diffraction study at 298 and $3 \mathrm{~K}$}

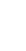

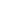

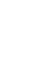

5

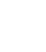

8

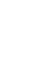

0

\section{Corresponding author: G. Diego GATTA}

Dipartimento di Scienze della Terra, Università degli Studi di Milano

Via Botticelli 23, I-20133 Milano, Italy

Tel. +39 02503 15607, Fax +39 02503 15597, E-Mail: diego.gatta@unimi.it

Manuscript submitted to Physics and Chemistry of Minerals 


\title{
H-bonding in lazulite: A single-crystal neutron diffraction study at 298 and $3 \mathrm{~K}$
}

\author{
G. Diego Gatta ${ }^{1,2}$, Pietro Vignola ${ }^{3}$, Nicola Rotiroti ${ }^{1}$ and Martin Meven ${ }^{4}$ \\ ${ }^{1}$ Dipartimento di Scienze della Terra, Università degli Studi di Milano, \\ Via Botticelli 23, I-20133 Milano, Italy \\ ${ }^{2}$ CNR-Istituto di Cristallografia, Via Amendola 122/O, I-70126 Bari, Italy \\ ${ }^{3}$ CNR-Istituto per la Dinamica dei Processi Ambientali, via Botticelli 23, I-20133, Milano, Italy \\ ${ }^{4}$ Institute of Crystallography, RWTH Aachen University, and Jülich Centre for Neutron Science (JCNS) at Heinz \\ Maier-Leibnitz Zentrum (MLZ), Lichtenbergstraße 1, D-85747 Garching, Germany
}

\begin{abstract}
The crystal structure and crystal chemistry of a lazulite from Crosscut Creek (Kulan Camp area, Dawson mining district, Yukon, Canada) was investigated by electron microprobe analysis in wavelength-dispersive mode (EMPA) and single-crystal neutron diffraction at 298 and $3 \mathrm{~K}$. Its empirical formula, based on EMPA data, is: $\left(\mathrm{Mg}_{0.871} \mathrm{Fe}_{0.127}\right)_{\Sigma 0.998} \mathrm{Al}_{2.030}\left(\mathrm{P}_{1.985} \mathrm{Ti}_{0.008} \mathrm{Si}_{0.007} \mathrm{O}_{4}\right)_{2}(\mathrm{OH})_{2}$. The neutron diffraction experiments at room and low $T$ proved that the $\mathrm{H}$-free structural model of lazulite previously reported, on the basis of X-ray structure refinement, is correct: the building unit of the lazulite structure consists of a group of three face-sharing (Al-octahedron) $+(\mathrm{Mg}, \mathrm{Fe}-$ octahedron $)+($ Al-octahedron $)$, connected to the adjacent one via a corner-shared OH-group and two corner-shared oxygen sites of the P-tetrahedron, to form a dense 3D-edifice. Only one crystallographically independent $\mathrm{H}$ site occurs in the structure of lazulite, forming a hydroxyl group with the O5 oxygen, with $\mathrm{O} 5-\mathrm{H}=0.9997 \AA$ at room temperature (corrected for riding motion effect). The H-bonding scheme in the structure of lazulite is now well defined: a bifurcated bonding scheme occurs with the $\mathrm{O} 4$ and $\mathrm{O} 2$ oxygen sites as acceptors. The two H-bonds are energetically different, as shown by their bonding geometry: the H-bond with the $\mathrm{O} 2$ site as acceptor is energetically more favorable, being $\mathrm{O} 5-\mathrm{H} \cdots \mathrm{O} 2=152.67(9)^{\circ}, \mathrm{O} 5 \cdots \mathrm{O} 2=3.014(1) \AA$ and $\mathrm{H} \cdots \mathrm{O} 2=2.114(1) \AA$, whereas that with $\mathrm{O} 4$ as acceptor is energetically more costly, being $\mathrm{O} 5-\mathrm{H} \cdots \mathrm{O} 4=135.73(8)^{\circ}, \mathrm{O} 5 \cdots \mathrm{O} 4=$ 3.156(1) $\AA$ and $\mathrm{H} \cdots \mathrm{O} 4=2.383(1) \AA$, at room temperature. No $T$-induced phase transition occurs within the $T$-range investigated. At low temperature, the $\mathrm{O} 5-\mathrm{H} \cdots \mathrm{O} 2$ bond is virtually identical to the room- $T$ one, whereas the effects of $T$ on $\mathrm{O} 5-\mathrm{H} \cdots \mathrm{O} 4$ are more pronounced, with significant differences of the $\mathrm{O}_{\text {donor }} \cdots \mathrm{O}_{\text {acceptor }}$ and $\mathrm{H}^{\cdots} \cdot \mathrm{O}_{\text {acceptor }}$ distances. The experimental findings of this study do not support the occurrence of $\mathrm{HPO}_{4}$ or $\mathrm{H}_{2} \mathrm{PO}_{4}$ units into the structure of lazulite, recently reported on the basis of infrared and Raman spectra.
\end{abstract}


Keywords: Lazulite; phosphates; single-crystal neutron diffraction; crystal chemistry; hydrogen bonding.

\section{Introduction}

Lazulite, $\mathrm{MgAl}_{2}\left(\mathrm{PO}_{4}\right)_{2}(\mathrm{OH})_{2}$, was described for the first time in the phosphate-bearing metaquarzites at Freissnitzgraen (Krieglach, Styria, Austria) by Klaproth (1795). This phosphate belongs to the "lazulite group" and forms a series with its Fe-analogue scorzalite, $\mathrm{FeAl}_{2}\left(\mathrm{PO}_{4}\right)_{2}(\mathrm{OH})_{2}(\mathrm{Pecora}$ and Fahey 1950). Lazulite occurs in metamorphic quartzites (phosphate-bearing quartzites), granitic pegmatites and low temperature hydrothermal veins in sedimentary or anchimetamorphic terranes.

Its crystal structure was solved in the $P 2_{1} / c$ space group, with unit-cell parameters $a \sim 7.16 \AA, b$ $\sim 7.26 \AA, c \sim 7.24 \AA, \beta \sim 120.7^{\circ}$, by Lindberg and Christ (1959), using a specimen from Minas Gerais, Brazil. The anisotropic structural model was later refined by Giuseppetti and Tadini (1983) in the same space group, using a specimen from the Graves Mountains (Georgia, U.S.A.). Giuseppetti and Tadini (1983) provided also the potential coordinates of one independent $\mathrm{H}$ site (forming a hydroxyl group with O-H distances of about $0.8 \AA$ ). The structure models of Lindberg and Christ (1959) and Giuseppetti and Tadini (1983) are mutually consistent and show that the triple-groups of face-sharing (Al-octahedron $)+(\mathrm{Mg}, \mathrm{Fe}-\mathrm{octahedron})+(\mathrm{Al}$-octahedron $)$ are connected to the adjacent ones by a cornershared $\mathrm{OH}$-group and two corner-shared oxygen sites of the P-tetrahedron (Fig. 1). However, in a more recent paper, based on infrared and Raman investigations of lazulite, Frost et al. (2013) reported evidence of bending modes ascribed to tetrahedral $\mathrm{PO}_{4}, \mathrm{HPO}_{4}$ and $\mathrm{H}_{2} \mathrm{PO}_{4}$ units. These experimental findings are not consistent with the structural model reported by Lindberg and Christ (1959) and Giuseppetti and Tadini (1983), in which $\mathrm{HPO}_{4}$ and $\mathrm{H}_{2} \mathrm{PO}_{4}$ groups are supposed not to occur. In addition, on the basis of their data, Frost et al. (2013) concluded that the proton on the hydroxyl units is apparently very mobile, promoting the formation of the monohydrogen and dihydrogen phosphate units.

In order to answer to the open questions about the structure of lazulite, and in the framework of a long-term project on the crystal-chemistry of hydrous phosphates (e.g., Gatta et al. 2013a, 2013b, 2014a, 2014b, 2015; Rotiroti et al. 2016), we have reinvestigated the crystal chemistry of lazulite by electron microprobe analysis in wavelength-dispersive mode (EMPA) and single-crystal neutron diffraction, in order to provide: $i)$ the reliable location of the proton site(s) and the real configuration of the $\mathrm{OH}$-group(s), for a full description of the H-bonds; ii) the anisotropic displacement parameters of all the atomic sites, H-site(s) included. In order to reduce the thermal displacement of the H-sites, and to confirm or deny the assumption on the proton mobility reported by Frost et al. (2013), single-crystal neutron diffraction data were collected at room temperature $(298 \mathrm{~K})$ and at low temperature $(3 \mathrm{~K})$. 


\section{Sample description and occurrence}

The crystal of lazulite used in this study belongs to the private collection of one of the authors (P.V., catalogue \#1493) and comes from the Crosscut Creek (Kulan Camp area, Dawson mining district, Yukon, Canada). The crystal was taken from the surface of a druse $(8 \times 5 \mathrm{~cm})$ representing a portion of the wall of a hydrothermally mineralized vein, with mineral association: lazulite + quartz + siderite. The phosphate rich clefts, in the Dawson mining district, are due to an unusual hydrothermal post-depositional history involving the whole Rapid Creek Formation (Robertson 1980, 1982). This complex sedimentary sequence, consisting of highly phosphatic ironstones, comprises (from the textural point of view) shales, mudstones, siltstones and sandstones. The phosphate mineral associations occur in the coarser layers as epigenetic fracture fillings in veins or vugs. Lazulite is part of a "complex vein", bearing a Ca-rich mineral association of the first type (i.e., quartz + siderite + lazulite + "apatite"; Robertson 1982). This association typically takes place in veins perpendicular to the bedding of the mudstone host. The veins are about $40 \mathrm{~cm}$ wide and up to $10 \mathrm{~m}$ long.

\section{Experimental methods}

Quantitative EMPA in wavelength-dispersive mode was obtained from a polished and carbon-coated section using a JEOL JXA-8200 microprobe at the Earth Sciences Department, University of Milano (ESD-UMI). The system was operated using an accelerating voltage of $15 \mathrm{kV}$, a beam current of $5 \mathrm{nA}$, a beam diameter of $5 \mu \mathrm{m}$, and a counting time of $30 \mathrm{~s}$ on the peaks and $10 \mathrm{~s}$ on the backgrounds. The following standards were used: graftonite KF-16 for P, Fe, Mn, and Ca; grossular for $\mathrm{Si}$ and $\mathrm{Al}$; $\mathrm{K}$-feldspar for $\mathrm{K}$; forsterite for $\mathrm{Mg}$; omphacite for $\mathrm{Na}$; ilmenite for $\mathrm{Ti}$; realgar for As. $\mathrm{Na}, \mathrm{K}, \mathrm{Ca}, \mathrm{Mn}$ and As were below the detection limits. The raw data were corrected for matrix effects using the protocol implemented in the JEOL suite of programs. The averaged composition of the lazulite used in this study is given in Table 1.

A single crystal of lazulite, optically homogeneous and free of inclusions or defects under a transmitted-light polarizing microscope, was selected for the X-ray and neutron diffraction experiments. A small fragment $\left(0.31 \times 0.27 \times 0.17 \mathrm{~mm}^{3}\right)$ was first investigated by single-crystal Xray diffraction. X-ray intensity data were collected at room temperature and up to $2 \theta_{\max } \cong 74^{\circ}$ with a Xcalibur - Oxford Diffraction diffractometer at the ESD-UMI, equipped with a CCD, monochromatized Mo-K $\alpha$ radiation and operated at $50 \mathrm{kV}$ and $30 \mathrm{~mA}$. The X-ray data collection was performed with a combination of $\varphi / \omega$ scans, step size of $1^{\circ}$ and an exposure time of $5 \mathrm{~s} /$ frame. The intensity data were integrated and indexed using the computer program CrysAlisPRO (Rigaku 2018). A total number of 8427 Bragg reflections, out of which 1062 were unique for symmetry 
(Laue class: $2 / m, R_{\text {int }}=0.041$ ), gave a metrically monoclinic unit-cell with: $a=7.139(1) \AA, b=$ 7.288(1), $c=7.236(1), \beta=120.33(2)^{\circ}$, according to the experimental findings of Giuseppetti and Tadini (1983), and the reflection conditions suggested the space group $P 2_{1} / C$ as highly likely.

A larger fragment from the same crystal $(2 \times 2 \times 3 \mathrm{~mm})$ was then used for the monochromatic neutron diffraction experiments at room and low temperature, using the diffractometer HEiDi at the hot source (fast neutrons) of the neutron source FRM II of the Heinz Maier-Leibnitz-Zentrum (MLZ), Germany. The diffractometer was equipped with a ${ }^{3} \mathrm{He}$ single counter detector for high sensitivity down to short wavelengths. Two set of diffraction data were first collected at room temperature: a first set of data was collected with a wavelength of the incident beam of 1.171(1) $\AA$ (Ge-311 monochromator, Er foil to suppress $\lambda / 3$ contamination) up to $2 \theta_{\max }=121^{\circ}\left(\sin (\theta) / \lambda=0.74 \AA^{-1}\right)$; a second set of data was collected at higher $\sin (\theta) / \lambda$ up to $0.89 \AA^{-}$ 1, with a wavelength of the incident beam of 0.795(1) $\AA$ (Ge-422 monochromator, Er foil to suppress $\lambda / 2$ contamination). In total, 2783 reflections were collected up to $d_{\min } \sim 0.7 \AA$ (with $-12 \leq$ $h \leq+12,-13 \leq k \leq+13$ and $-12 \leq l \leq+12$, Table 2 ), using pure $\omega$-scan and $\omega-2 \theta$ scan strategy as reported in Table 2, out of which 1755 were unique for symmetry and 1452 with $F_{\mathrm{o}}>4 \sigma\left(F_{\mathrm{o}}\right)$. Integrated intensities were then corrected for the Lorentz effect; absorption correction was found to be negligible. After the corrections, the discrepancy factor among symmetry-related reflections (Laue class: $2 / m$ ) was $R_{\text {int }}=0.0371$ (Table 2).

Low-temperature diffraction data were collected with a wavelength of the incident beam of $0.795(1) \AA$. The sample was fixed on an aluminium pin $(0.8 \mathrm{~mm}$ diameter) and mounted on a closed-cycle cryostat to reach a minimum temperature of $3.0 \mathrm{~K}(+/-0.1 \mathrm{~K})$. A total number of 2047 reflections were collected up to $d_{\min } \sim 0.7 \AA$ (with $-11 \leq h \leq+11,-11 \leq k \leq+11$ and $-11 \leq l \leq+11$, Table 2), using a pure $\omega$-scan strategy, out of which 1292 were unique for symmetry and 986 with $F_{0}>4 \sigma\left(F_{\mathrm{o}}\right)$. After corrected for the Lorentz effect, the discrepancy factor among symmetry-related reflections (Laue class: $2 / m$ ) was $R_{\text {int }}=0.0303$ (Table 2). Further details pertaining to the neutron data collections, at room and low $T$, are given in Table 2 .

For both the data collections (i.e., room and low T), the lattice was found to be metrically monoclinic, and the reflections conditions were consistent with the space group $P 2_{1} / c$, as previously reported by Giuseppetti and Tadini (1983). The evolution of intensity and full-width-at-halfmaximum of three selected Bragg reflections (i.e., 00-6, 040 and -400) were followed between room and low $T$ (Fig. 2), showing no evidence of phase transition within the $T$-range investigated.

Anisotropic crystal-structure refinements, based on the neutron data collected at room and low $T$, were done in the space group $P 2{ }_{1} / C$ using the SHELXL-97 software (Sheldrick 1997, 2008), starting from the H-free structure model of Giuseppetti and Tadini (1983), and using the neutron 
scattering lengths of $\mathrm{Mg}, \mathrm{Fe}, \mathrm{Al}, \mathrm{P}, \mathrm{O}$ and $\mathrm{H}$ from Sears (1986). Secondary isotropic extinction effect was corrected according to the formalism of Larson (1967), as implemented in the SHELXL package. After a few cycles of refinement, convergence was achieved with one (unique) intense negative residual peak in the final difference-Fourier map of the nuclear density (Fig. 3), located at ca. $1 \AA$ from the $\mathrm{O} 5$ site. Further cycles of refinement were then done with $\mathrm{H}$ site assigned to this peak (as H has a negative neutron scattering length, Sears 1986). Convergence was achieved after a few cycles of refinement, with all the principal mean-square atomic displacement parameters positive, including those for the $\mathrm{H}$ site. At the end of the refinement, the variance-covariance matrix showed no significant correlation among the refined variables. Further details pertaining to structure refinement strategy are given in Table 2. Atomic coordinates and displacement parameters are listed in Tables 3 and 4; selected interatomic distances and angles are given in Table 5.

\section{Results and Discussion}

The EMPA data of the lazulite sample used in this study confirms its ideal formula: $\mathrm{MgAl}_{2}\left(\mathrm{PO}_{4}\right)_{2}(\mathrm{OH})_{2}$ (Pecora and Fahey 1950, Lindberg and Christ 1959). P (in tetrahedral coordination) is replaced by a very modest fraction of $\mathrm{Ti}$ and $\mathrm{Si}, \mathrm{Al}$ (in octahedral configuration) does not show any substituent, and $\mathrm{Mg}$ is replaced by $\mathrm{Fe}$ (Table 1). The $\mathrm{Mg}$ vs. Fe substitution is expected, as lazulite (ideally $\mathrm{MgAl}_{2}\left(\mathrm{PO}_{4}\right)_{2}(\mathrm{OH})_{2}$ ) and scorzalite (ideally $\mathrm{FeAl}_{2}\left(\mathrm{PO}_{4}\right)_{2}(\mathrm{OH})_{2}$ ) are supposed to form a complete isomorphous series (Pecora and Fahey 1950; Gheith 1953). The empirical formula of lazulite from Crosscut Creek used in this study is: $\left(\mathrm{Mg}_{0.871} \mathrm{Fe}_{0.127}\right)_{\Sigma 0.998} \mathrm{Al}_{2.030}\left(\mathrm{P}_{1.985} \mathrm{Ti}_{0.008} \mathrm{Si}_{0.007} \mathrm{O}_{4}\right)_{2}(\mathrm{OH})_{2}$ (Table 1).

The neutron structure refinements of this study, based on intensity data collected at 298 and 3 $\mathrm{K}$, provide a general structural model of lazulite consistent with those previously reported by Lindberg and Christ (1959) and Giuseppetti and Tadini (1983), based on single-crystal X-ray intensity data collected at room temperature: the building unit of the lazulite structure consists of a group of three face-sharing (Al-octahedron) $+(\mathrm{Mg}, \mathrm{Fe}-$ octahedron $)+(\mathrm{Al}$-octahedron $)$, connected to the adjacent one via a corner-shared $\mathrm{OH}$-group and two corner-shared oxygen sites of the Ptetrahedron, to form a dense 3D-edifice (Fig. 1). The P-tetrahedron is the most regular coordination polyhedron [with $\Delta(\mathrm{P}-\mathrm{O})_{\max } \sim 0.03 \AA$, i.e., the difference between the longest and the shortest bond distances], the $(\mathrm{Mg}, \mathrm{Fe})$-octehedron is slightly more distorted $\left[\Delta(\mathrm{Mg}, \mathrm{Fe}-\mathrm{O})_{\max } \sim 0.06 \AA\right]$, whereas the Al-octahedron is strongly deformed $\left[\Delta(\mathrm{Al}-\mathrm{O})_{\max } \sim 0.20 \AA\right]$. Only one crystallographically independent $\mathrm{H}$ site occurs in the structure of lazulite, forming a hydroxyl group with the O5 oxygen, with $\mathrm{O} 5-\mathrm{H}^{*}=0.9997 \AA$ at room temperature (*corrected for riding motion effect, Table 5). The H- 
bonding scheme in the structure of lazulite is now well defined: a bifurcated bonding scheme occurs with the $\mathrm{O} 4$ and $\mathrm{O} 2$ oxygen sites as acceptors (Table 5). The two H-bonds are energetically different, as shown by their bonding geometry: the H-bond with the $\mathrm{O} 2$ site as acceptor is energetically more favorable, being $\mathrm{O} 5-\mathrm{H} \cdots \mathrm{O} 2=152.67(9)^{\circ}, \mathrm{O} 5 \cdots \mathrm{O} 2=3.014(1) \AA$ and $\mathrm{H} \cdots \mathrm{O} 2=$ 2.114(1) $\AA$, whereas that with $\mathrm{O} 4$ as acceptor is energetically more costly, being O5-H $\cdots \mathrm{O} 4=$ $135.73(8)^{\circ}, \mathrm{O} 5 \cdots \mathrm{O} 4=3.156(1) \AA$ and $\mathrm{H} \cdots \mathrm{O} 4=2.383(1) \AA$, at room temperature. At low temperature, the $\mathrm{O} 5-\mathrm{H} \cdots \mathrm{O} 2$ bond is virtually identical to the room- $T$ one (differences are within $0.001 \AA$ and $0.1^{\circ}$, Table 5), whereas the effects of $T$ on $\mathrm{O} 5-\mathrm{H} \cdots \mathrm{O} 4$ are more pronounced, with significant differences of the $\mathrm{O}_{\text {donor }} \cdots \mathrm{O}_{\text {acceptor }}$ and $\mathrm{H}^{\cdots} \mathrm{O}_{\text {acceptor }}$ distances (i.e., $\sim 0.02 \AA$, Table 5).

The H-bonding scheme in the structure of lazulite here described is compatible with the findings based on infrared and Raman spectroscopies (e.g., Frost et al. 2013, RRUFF database: http://rruff.info/Lazulite), as IR and Raman spectra, in the region of the $\mathrm{OH}$ stretching active modes, show evidence of more than one unique H-bond. The description of the IR and Raman mode in lazulite provided by Frost et al. (2013) is likely affected by misinterpretation: the structure does not contain $\mathrm{HPO}_{4}$ or $\mathrm{H}_{2} \mathrm{PO}_{4}$ units, and, in addition, the conclusion "The proton on the hydroxyl units is apparently very mobile and enables the formation of the monohydrogen and dihydrogen phosphate units” (Frost et al. 2013) is inconsistent with our experimental findings and, in general, not plausible. We expect that a more robust description of the active IR and Raman vibrational modes will be delivered on the basis of the structure models of this study.

As shown by the root-mean-square components of the displacement ellipsoids at room $T$ (Table 4), the $\mathrm{H}$ site has the largest anisotropic displacement parameters, followed by the oxygen sites and then by the cationic sites. However, the disordered $(\mathrm{Mg}, \mathrm{Fe})$ site shows the largest displacement parameters among the cationic sites (i.e., $\mathrm{Mg}$-Fe, $\mathrm{Al}$ and $\mathrm{P}$, Table 4). At low T, there is a general reduction of magnitude of the atomic displacement ellipsoids (by 10-40\%), but not of their ellipticity ratio (Fig. 4, Table 4).

The Mg vs. Fe distribution is supposed not to change (at a significant level) between room and low $T$, as the mechanisms that promote intra-crystalline disordering, in this class of materials, are usually activated at high $T$. The slight difference between the refined $\mathrm{Mg} v$. Fe fraction at the octahedral site at room and low $T$ are within $3 \sigma$ (Table 3 ), and therefore not significant. On the average, we can assume that the chemical formula of lazulite based on the neutron structure refinements is $\left(\mathrm{Mg}_{0.88(2)} \mathrm{Fe}_{0.12(2)}\right) \mathrm{Al}_{2}\left(\mathrm{PO}_{4}\right)_{2}(\mathrm{OH})_{2}$ (Table 3), in excellent agreement with the EMPA data. 


\section{Acknowledgements}

The authors acknowledge the Heinz Maier-Leibnitz Zentrum (MLZ) in Garching, Germany, for the allocation of neutron beam time at the single-crystal diffractometer HEIDI, operated by RWTH Aachen University and Jülich Centre for Neutron Science, Forschungszentrum Jülich (JARA cooperation). GDG and NR acknowledge the support of the Italian Ministry of Education (MIUR) through the project "Dipartimenti di Eccellenza 2018-2022". E. Schingaro and an anonymous reviewer are thanked.

\section{References}

Busing WR, Levy HA (1964) The effect of thermal motion on the estimation of bond lengths from diffraction measurements. Acta Crystallogr 17:142-146.

Frost RL, Xi Y, Beganovic M, Belotti FM, Scholz R (2013) Vibrational spectroscopy of the phosphate mineral lazulite - $(\mathrm{Mg}, \mathrm{Fe}) \mathrm{Al}_{2}\left(\mathrm{PO}_{4}\right)_{2}(\mathrm{OH})_{2}$ found in the Minas Gerais, Brazil. Spectrochim Acta Part A (Molecular and Biomolecular Spectroscopy) 107:241-247.

Gatta GD, Vignola P, Meven M, Rinaldi R (2013a) Neutron diffraction in gemology: Single-crystal diffraction study of brazilianite, $\mathrm{NaAl}_{3}\left(\mathrm{PO}_{4}\right)_{2}(\mathrm{OH})_{4}$. Am Mineral 98:1624-1630.

Gatta GD, Nénert G, Vignola P (2013b) Coexisting hydroxyl groups and $\mathrm{H}_{2} \mathrm{O}$ molecules in minerals: A single-crystal neutron diffraction study of eosphorite, $\mathrm{MnAlPO}_{4}(\mathrm{OH})_{2} \cdot \mathrm{H}_{2} \mathrm{O}$. Am Mineral 98:1297-1301.

Gatta GD, Jacobsen SD, Vignola P, McIntyre GJ, Guastella G, Abate LF (2014a) Single-crystal neutron diffraction and Raman spectroscopic study of hydroxylherderite, $\mathrm{CaBePO}_{4}(\mathrm{OH}, \mathrm{F})$. Mineral Mag, 78, 723-737.

Gatta GD, Vignola P, Meven M (2014b) On the complex H-bonding network in paravauxite, $\mathrm{Fe}^{2+} \mathrm{Al}_{2}\left(\mathrm{PO}_{4}\right)_{2}(\mathrm{OH})_{2} \cdot 8 \mathrm{H}_{2} \mathrm{O}$ : A single-crystal neutron diffraction study. Mineral Mag 78:841850 .

Gatta GD, Redhammer GJ, Vignola P, Meven M, McIntyre GJ (2015) Single-crystal neutron diffraction and Mössbauer spectroscopic study of hureaulite, $(\mathrm{Mn}, \mathrm{Fe})_{5}\left(\mathrm{PO}_{4}\right)_{2}\left(\mathrm{HPO}_{4}\right)_{2}\left(\mathrm{H}_{2} \mathrm{O}\right)_{4}$. Eur J Mineral 28:93-103.

Gatta GD, Rotiroti N, Cámara F, Meven M (2018) On the labyrinthine world of arsenites: a singlecrystal neutron and X-ray diffraction study of cafarsite. Phys Chem Minerals 45:819-829.

Gheith MA (1953) Lipscombite: a new synthetic "iron lazulite". Am Mineral 38:612-628.

Giuseppetti G, Tadini C (1983) Lazulite, $(\mathrm{Mg}, \mathrm{Fe}) \mathrm{Al}_{2}(\mathrm{OH})_{2}\left(\mathrm{PO}_{4}\right)_{2}$, structure refinement and hydrogen bonding. Neu Jb Mineral Mh. 1983:410-416. 
Klaproth MH (1795) Beiträge zur chemischen Kenntnis der Mineralkörpe (first edition), Heinrich August Rottman, Berlin.

Larson AC (1967) Inclusion of secondary extinction in least-squares calculations. Acta Crystallogr $23: 664-665$.

Lindberg LM, Christ CL (1959) Crystal structures of the isostructural minerals lazulite, scorzalite and barbosalite. Acta Crystallogr 12:695-697.

Pecora WT, Fahey JJ (1950) The lazulite-scorzalite isomorphous series. Am Mineral 35:1-18.

Rigaku (2018) CrysAlisPRO, computer suite. Rigaku Oxford Diffraction.

Robertson BT (1980) Stratigraphic setting of some new and rare phosphate minerals in the Yukon Territory. M.Sc. Thesis, University of Saskatchewan, Saskatoon, Canada.

Robertson BT (1982) Occurrence of epigenetic phosphate minerals in a phosphatic iron-formation, Yukon Territory. Can Mineral 20:177-187.

Rotiroti N, Vignola P, Bersani D, Simmons WB, Falster AU, Whitmore RW, Nizamoff J, Lotti P, Risplendente A, Pavese A (2016) On the crystal-chemistry of bjarebyite, $\mathrm{BaMn}_{2}^{2+}{ }_{2} \mathrm{Al}_{2}\left(\mathrm{PO}_{4}\right)_{3}(\mathrm{OH})_{3}$, from the Palermo \#1 pegmatite, Grafton County, New Hampshire, USA. Can Mineral 54:1033-1041.

Sears VF (1986) Neutron Scattering Lengths and Cross-Sections. In K. Sköld and D.L. Price, Eds., Neutron Scattering, Methods of Experimental Physics, Vol. 23A, 521-550. Academic Press, New York.

Sheldrick GM (1997) SHELXL-97. Programs for crystal structure determination and refinement. University of Göttingen, Germany.

Sheldrick GM (2008) A short history of SHELX. Acta Crystallogr A64:112-122. 
Table 1. EMPA chemical analysis of lazulite from Crosscut Creek (Kulan Camp area, Dawson mining district, Yukon, Canada). Average composition based on 9 point-analysis.

\begin{tabular}{lcccc}
\hline & $w t \%$ & e.s.d. & & *a.p.f.u. \\
\hline $\mathrm{P}_{2} \mathrm{O}_{5}$ & 45.61 & 0.20 & $\mathrm{P}$ & 1.98500 \\
$\mathrm{SiO}_{2}$ & 0.13 & 0.05 & $\mathrm{Si}$ & 0.007 \\
$\mathrm{TiO}_{2}$ & 0.21 & 0.10 & $\mathrm{Ti}$ & 0.0981 \\
$\mathrm{Al}_{2} \mathrm{O}_{3}$ & 33.51 & 0.18 & sum & $\mathbf{2 . 0 9 9} 2$ \\
$\mathrm{FeO}$ & 2.96 & 0.18 & & \\
$\mathrm{MgO}$ & 11.37 & 0.12 & $\mathrm{Al}$ & $\mathbf{2 . 0 3 0 3}$ \\
$\mathrm{H}_{2} \mathrm{O}^{* *}$ & 5.83 & 0.03 & & 304 \\
Total & 99.63 & & $\mathrm{Fe}$ & 0.127 \\
& & & $\mathrm{Mg}$ & 0.8795 \\
& & & sum & $\mathbf{0 . 9 9 8}$ \\
& & & & \\
& & & $\mathrm{H}^{* *}$ & $\mathbf{2 . 0 0 0 7}$ \\
\hline
\end{tabular}

Notes: *calculated on the basis of $2(\mathrm{P}+\mathrm{Si}+\mathrm{Ti})$ a.p.f.u.; ** calculate $388^{\mathrm{n}}$ the basis of $2 \mathrm{OH}$-groups. 
Table 2. Details of neutron data collections and refinements of lazulite.

312

313

314

315

316

317

318

319

320

321

322

323

324

325

326

327

328

329

330

331

332

333

334

335

336

337

338

\begin{tabular}{|c|c|}
\hline 298 & 3 \\
\hline Prism & Prism \\
\hline $2 \times 2 \times 3$ & $2 \times 2 \times 3$ \\
\hline$a=7.139(1) \AA$ & $a=7.137(1) \AA$ \\
\hline$b=7.288(1) \AA$ & $b=7.249(1) \AA$ \\
\hline$c=7.236(1) \AA$ & $c=7.201(1) \AA$ \\
\hline$\beta=120.33(2)^{\circ}$ & $\beta=120.38(5)^{\circ}$ \\
\hline $\begin{array}{c}\mathrm{MgAl}_{2}\left(\mathrm{PO}_{4}\right)_{2}(\mathrm{OH})_{2} \\
P 2_{1} / c\end{array}$ & $\begin{array}{c}\mathrm{MgAl}_{2}\left(\mathrm{PO}_{4}\right)_{2}(\mathrm{OH})_{2} \\
P 2_{1} / c\end{array}$ \\
\hline 2 & 2 \\
\hline neutron & neutron \\
\hline $1.171(1), 0.795(1)$ & $0.795(1)$ \\
\hline HEiDi-4circle & HEiDi-4circle \\
\hline$\omega$-scan, $\omega-2 \theta$ scan & $\omega$-scan \\
\hline$\sim 0.7$ & $\sim 0.7$ \\
\hline$-12 \leq h \leq+12$ & $-11 \leq h \leq+11$ \\
\hline$-13 \leq k \leq+13$ & $-11 \leq k \leq+11$ \\
\hline$-12 \leq l \leq+12$ & $-11 \leq l \leq+11$ \\
\hline 2783 & 2047 \\
\hline 1755 & 1292 \\
\hline 1452 & 986 \\
\hline 82 & 81 \\
\hline 0.0371 & 0.0303 \\
\hline 0.0381 & 0.0407 \\
\hline 0.0328 & 0.0293 \\
\hline 0.0580 & 0.0528 \\
\hline 0.0578 & 0.0454 \\
\hline 1.627 & 1.291 \\
\hline$-0.9 /+0.8$ & $-0.7 /+0.6$ \\
\hline
\end{tabular}


Table 3. Refined fractional atomic coordinates and equivalent/isotropic displacement factors $\left(\AA^{2}\right)$, 340 based on the neutron structure refinements of lazulite at 298 and $3 \mathrm{~K}$. $U_{e q}$ is defined as one-third of 341 the trace of the orthogonalised $U_{i j}$ tensor.

\begin{tabular}{l|l|llll}
\hline Site & S.o.f. & x/a & $y / b$ & $z / c$ & $U_{\text {eq }}$ \\
\hline 298 K & & & & & \\
Mg & Mg 0.895(5), Fe 0.105(5) & 0 & 0 & 0 & $0.00775(13)$ \\
Al & Al 1 & $-0.26734(8)$ & $0.26678(8)$ & $0.00630(10)$ & $0.00574(10)$ \\
P & P 1 & $0.24810(6)$ & $0.38541(5)$ & $0.24507(7)$ & $0.00544(8)$ \\
O1 & O 1 & $-0.21236(6)$ & $0.01394(5)$ & $0.10605(7)$ & $0.00877(8)$ \\
O2 & O 1 & $-0.28791(6)$ & $0.49997(5)$ & $-0.09320(7)$ & $0.00973(8)$ \\
O3 & O 1 & $0.04396(5)$ & $0.26401(5)$ & $0.12474(6)$ & $0.00873(8)$ \\
O4 & O 1 & $-0.56186(5)$ & $0.24243(6)$ & $-0.12910(6)$ & $0.00948(8)$ \\
O5 & O 1 & $-0.26002(6)$ & $0.14638(5)$ & $-0.24144(6)$ & $0.00735(8)$ \\
H & H 1 & $-0.38416(14)$ & $0.06336(13)$ & $-0.30098(15)$ & $0.02493(18)$ \\
\hline 3 K & Mg 0.876(7), Fe 0.124(7) & 0 & & & \\
Mg & Al 1 & $-0.26714(13)$ & $0.26665(11)$ & $0.00617(14)$ & $0.00212(13)$ \\
Al & P 1 & $0.24796(9)$ & $0.38489(7)$ & $0.24490(9)$ & $0.00209(8)$ \\
P & O 1 & $-0.21312(8)$ & $0.01366(7)$ & $0.10528(8)$ & $0.00330(9)$ \\
O1 & $-0.28733(8)$ & $0.50023(7)$ & $-0.09256(8)$ & $0.00351(9)$ \\
O2 & O 1 & $0.04361(8)$ & $0.26334(7)$ & $0.12493(8)$ & $0.00339(9)$ \\
O3 & O 1 & $-0.56178(8)$ & $0.24354(7)$ & $-0.12952(8)$ & $0.00351(9)$ \\
O4 & O 1 & $-0.25998(9)$ & $0.14669(7)$ & $-0.24130(9)$ & $0.00317(9)$ \\
O5 & O 1 & $-0.38447(18)$ & $0.06335(16)$ & $-0.30080(19)$ & $0.0181(2)$ \\
H & H 1 & & & & \\
\hline
\end{tabular}


Table 4. Refined displacement parameters $\left(\AA^{2}\right)$ in the expression: $-2 \pi^{2}\left[\left(h a^{*}\right)^{2} U_{11}+\ldots+2 h k a^{*} b^{*} U_{12}\right.$ $\left.+\ldots+2 k l b^{*} c^{*} U_{23}\right]$ and root-mean-square displacement amplitude (RMS, $\AA$ ), based on the neutron structure refinements of lazulite at 298 and $3 \mathrm{~K}$.

\begin{tabular}{|c|c|c|c|c|c|c|c|c|c|c|}
\hline & $U_{11}$ & $U_{22}$ & $U_{33}$ & $U_{12}$ & $U_{13}$ & $U_{23}$ & $\begin{array}{l}R M S- \\
\text { min }\end{array}$ & $\begin{array}{l}\text { RMS- } \\
\text { mid }\end{array}$ & $\begin{array}{l}\text { RMS- } \\
\max \end{array}$ & $\max / \min$ \\
\hline \multicolumn{11}{|l|}{$298 K$} \\
\hline $\mathrm{Mg}$ & $0.0085(2)$ & $0.0065(2)$ & $0.0097(2)$ & $0.0017(1)$ & $0.0056(2)$ & $0.0006(2)$ & 0.0714 & 0.0888 & 0.1013 & 1.42 \\
\hline $\mathrm{Al}$ & $0.0055(2)$ & $0.0057(2)$ & $0.0057(2)$ & $0.0001(1)$ & $0.0026(2)$ & $0.0002(2)$ & 0.0732 & 0.0753 & 0.0786 & 1.07 \\
\hline $\mathrm{P}$ & $0.0054(1)$ & $0.0051(1)$ & $0.0057(1)$ & $-0.0002(1)$ & $0.0027(1)$ & $-0.0001(1)$ & 0.0709 & 0.0739 & 0.0764 & 1.08 \\
\hline $\mathrm{O} 1$ & $0.0115(1)$ & $0.0075(1)$ & $0.0098(2)$ & $0.0017(1)$ & $0.0072(1)$ & $0.0024(1)$ & 0.0752 & 0.0880 & 0.1138 & 1.51 \\
\hline $\mathrm{O} 2$ & $0.0149(2)$ & $0.0068(1)$ & $0.0108(2)$ & $0.0008(1)$ & $0.0090(1)$ & $0.0018(1)$ & 0.0734 & 0.0916 & 0.1241 & 1.69 \\
\hline $\mathrm{O} 3$ & $0.0058(1)$ & $0.0082(1)$ & $0.0104(2)$ & $-0.0011(1)$ & $0.0028(1)$ & $-0.0024(1)$ & 0.0722 & 0.0886 & 0.1145 & 1.58 \\
\hline $\mathrm{O} 4$ & $0.0061(1)$ & $0.0101(1)$ & $0.0107(2)$ & $-0.0017(1)$ & $0.0032(1)$ & $-0.0028(1)$ & 0.0737 & 0.0962 & 0.1173 & 1.59 \\
\hline O5 & $0.0083(1)$ & $0.0074(1)$ & $0.0061(1)$ & $-0.0006(1)$ & $0.0034(1)$ & $0.0001(1)$ & 0.0777 & 0.0842 & 0.0944 & 1.22 \\
\hline $\mathrm{H}$ & $0.0250(3)$ & $0.0285(4)$ & $0.0202(4)$ & $-0.0140(3)$ & $0.0106(3)$ & $-0.0057(3)$ & 0.1122 & 0.1448 & 0.2031 & 1.81 \\
\hline \multicolumn{11}{|l|}{$3 K$} \\
\hline $\mathrm{Mg}$ & $0.0037(3)$ & $0.0024(3)$ & $0.0030(3)$ & $0.0006(2)$ & $0.0020(2)$ & $0.0001(2)$ & 0.0446 & 0.0523 & 0.0625 & 1.40 \\
\hline $\mathrm{Al}$ & $0.0030(3)$ & $0.0018(3)$ & $0.0020(3)$ & $-0.0001(2)$ & $0.0016(2)$ & $0.0001(2)$ & 0.0380 & 0.0438 & 0.0547 & 1.44 \\
\hline $\mathrm{P}$ & $0.0025(2)$ & $0.0018(2)$ & $0.0021(2)$ & $-0.0001(2)$ & $0.0013(1)$ & $-0.0003(2)$ & 0.0390 & 0.0468 & 0.0505 & 1.29 \\
\hline $\mathrm{O} 1$ & $0.0047(2)$ & $0.0027(2)$ & $0.0035(2)$ & $0.0002(2)$ & $0.0029(2)$ & $0.0011(2)$ & 0.0374 & 0.0593 & 0.0704 & 1.88 \\
\hline $\mathrm{O} 2$ & $0.0055(2)$ & $0.0023(2)$ & $0.0038(2)$ & $0.0001(2)$ & $0.0033(2)$ & $0.0007(2)$ & 0.0413 & 0.0562 & 0.0751 & 1.82 \\
\hline $\mathrm{O} 3$ & $0.0031(2)$ & $0.0029(2)$ & $0.0038(2)$ & $-0.0009(2)$ & $0.0015(2)$ & $-0.0008(1)$ & 0.0449 & 0.0620 & 0.0657 & 1.46 \\
\hline $\mathrm{O} 4$ & $0.0030(2)$ & $0.0036(2)$ & $0.0037(2)$ & $-0.0007(1)$ & $0.0015(2)$ & $-0.0010(1)$ & 0.0490 & 0.0589 & 0.0683 & 1.39 \\
\hline O5 & $0.0042(2)$ & $0.0031(2)$ & $0.0027(2)$ & $-0.0003(1)$ & $0.0020(1)$ & $0.0001(1)$ & 0.0470 & 0.0552 & 0.0652 & 1.39 \\
\hline $\mathrm{H}$ & $0.0179(4)$ & $0.0192(5)$ & $0.0164(4)$ & $-0.0108(4)$ & $0.0081(4)$ & $-0.0043(3)$ & 0.0880 & 0.1301 & 0.1719 & 1.95 \\
\hline
\end{tabular}

(1)


367 Table 5. Relevant bond distances $(\AA)$ and angles $\left(^{\circ}\right)$ based on the neutron structure refinements at $368 \quad 298$ and $3 \mathrm{~K}$.

\begin{tabular}{|c|c|c|}
\hline & $298 K$ & $3 K$ \\
\hline $\mathrm{Mg}-\mathrm{O} 1 \mathrm{x} 2$ & $2.0181(5)$ & $2.0161(6)$ \\
\hline $\mathrm{Mg}-\mathrm{O} 3 \times 2$ & $2.0807(4)$ & $2.0657(5)$ \\
\hline $\mathrm{Mg}-\mathrm{O} 5 \times 2$ & $2.0882(6)$ & $2.0813(6)$ \\
\hline $\mathrm{Al}-\mathrm{O} 1$ & $1.9454(7)$ & $1.9347(10)$ \\
\hline $\mathrm{A} 1-\mathrm{O} 2$ & $1.8224(7)$ & $1.8137(10)$ \\
\hline $\mathrm{Al}-\mathrm{O} 3$ & $1.9366(7)$ & $1.9319(10)$ \\
\hline $\mathrm{Al}-\mathrm{O} 4$ & $1.8253(8)$ & $1.8239(10)$ \\
\hline $\mathrm{Al}-\mathrm{O} 5$ & $2.0200(8)$ & $2.0066(11)$ \\
\hline $\mathrm{Al}$ - O5' & $1.9074(8)$ & $1.9000(11)$ \\
\hline P - O1 & $1.5429(5)$ & $1.5389(8)$ \\
\hline $\mathrm{P}-\mathrm{O} 2$ & $1.5171(6)$ & $1.5125(8)$ \\
\hline $\mathrm{P}-\mathrm{O} 3$ & $1.5438(6)$ & $1.5412(7)$ \\
\hline $\mathrm{P}-\mathrm{O} 4$ & $1.5133(6)$ & $1.5121(7)$ \\
\hline $\mathrm{O} 5-\mathrm{H}$ & $0.9755(9)$ & $0.9761(11)$ \\
\hline $\mathrm{O} 5-\mathrm{H}^{*}$ & 0.9997 & 0.9968 \\
\hline $\mathrm{O} 5-\mathrm{H} \cdots \mathrm{O} 2$ & $152.67(9)$ & $152.7(1)$ \\
\hline $\mathrm{O} 5 \cdots \mathrm{O} 2$ & $3.014(1)$ & $3.015(1)$ \\
\hline $\mathrm{H} \cdots \mathrm{O} 2$ & $2.114(1)$ & $2.113(1)$ \\
\hline $\mathrm{O} 5-\mathrm{H} \cdots \mathrm{O} 4$ & $135.73(8)$ & $135.6(1)$ \\
\hline $\mathrm{O} 5 \cdots \mathrm{O} 4$ & $3.156(1)$ & $3.135(1)$ \\
\hline $\mathrm{H} \cdots \mathrm{O} 4$ & $2.383(1)$ & $2.362(1)$ \\
\hline
\end{tabular}



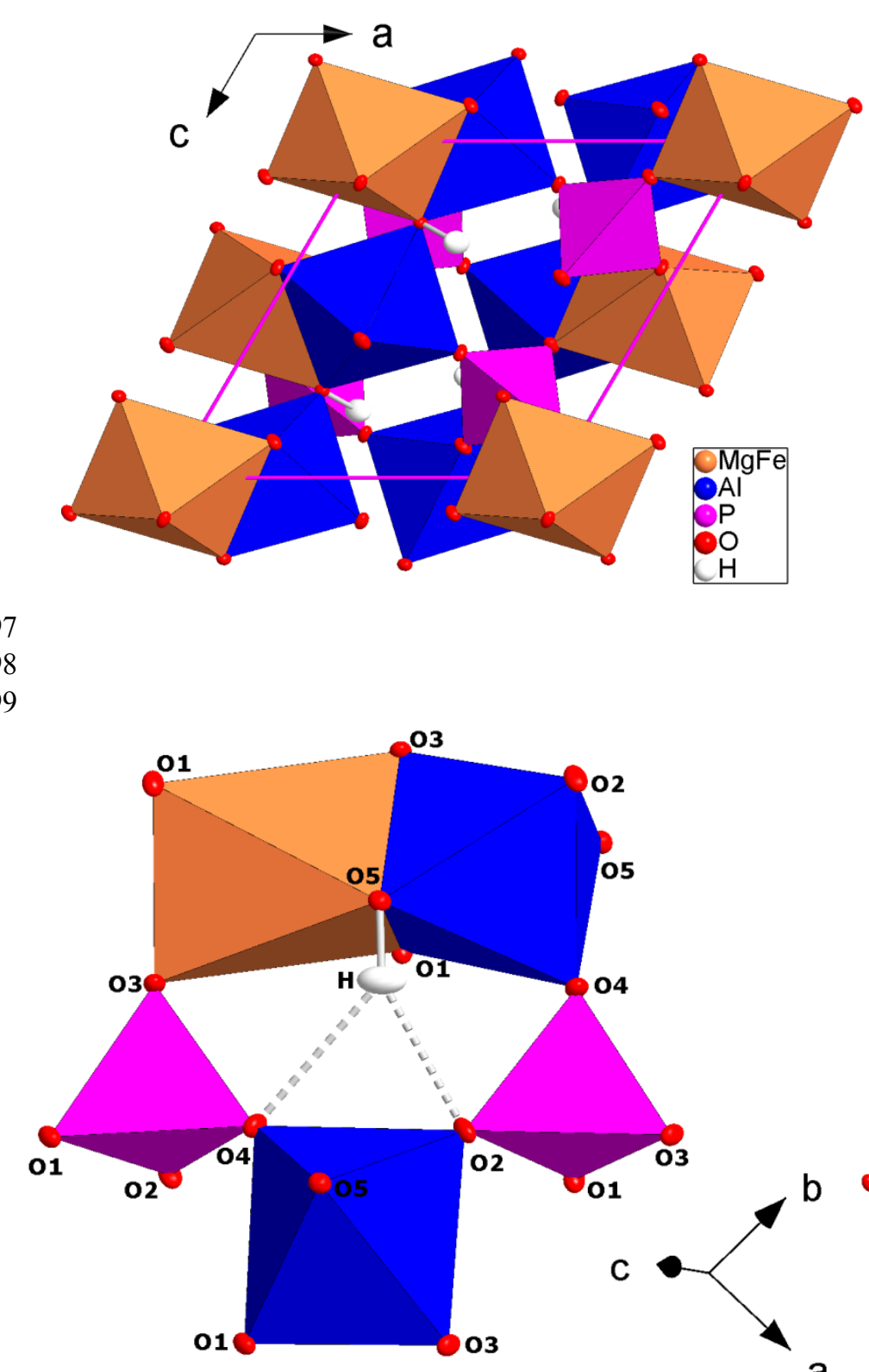

Figure 1. The crystal structure of lazulite, viewed down [010] (top left) and [100] (top right), and its bifurcated H-bonding scheme (bottom left), based on the neutron structure refinement of this study (intensity data collected at $298 \mathrm{~K}$ ). Displacement ellipsoid probability factor: $50 \%$. In bracket: the triple face-sharing $\mathrm{Al}_{\text {oct }}-(\mathrm{Mg}, \mathrm{Fe})_{\text {oct }}-\mathrm{Al}_{\text {oct }}$ building unit (bottom right).
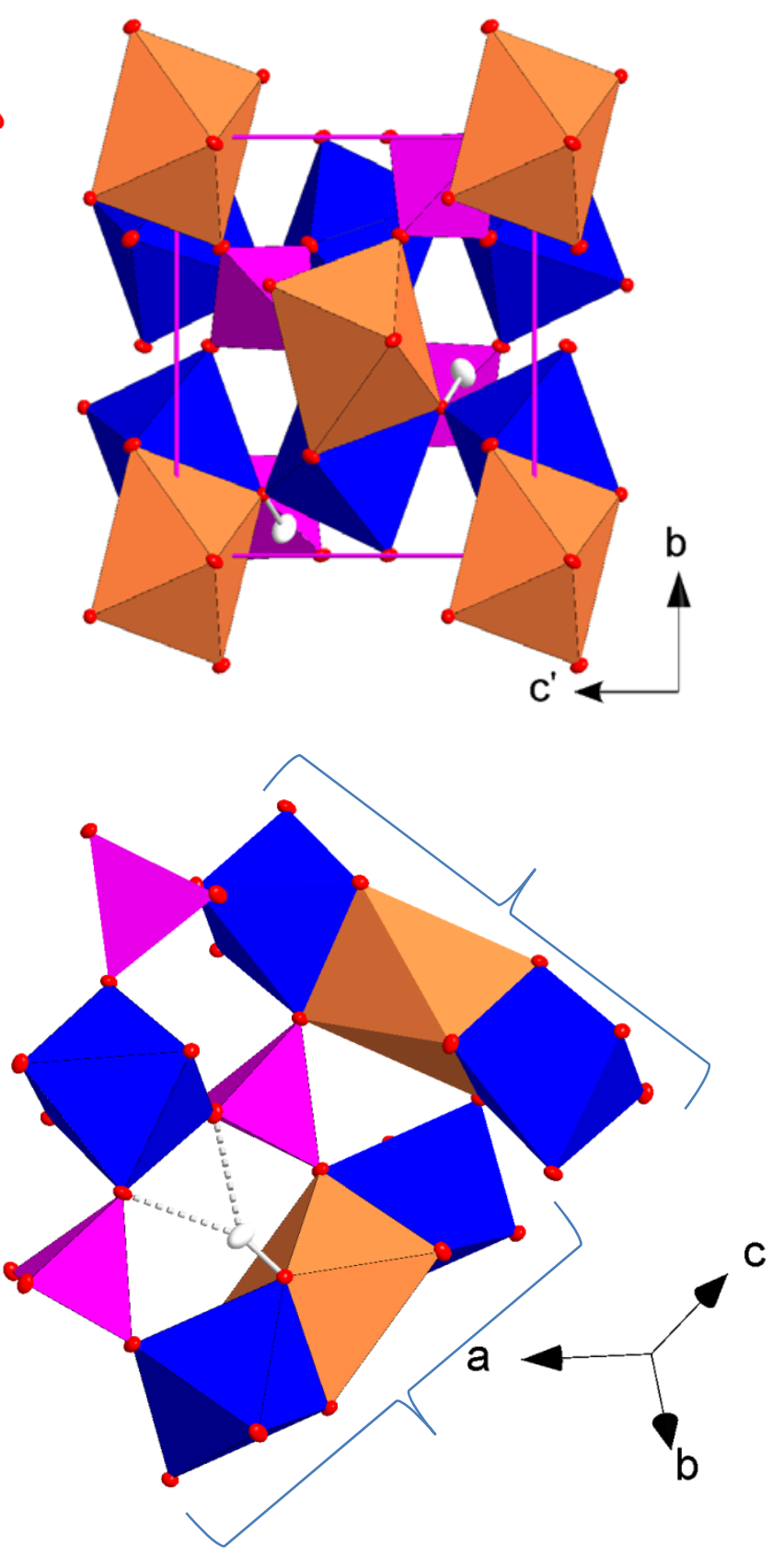
Figure 2. Evolution of the integrated intensities and of the full-width-at-half-maxima (FWHM) of the Bragg reflections 00-6 (top left and right), 040 (mid left and right) and -400 (bottom left and
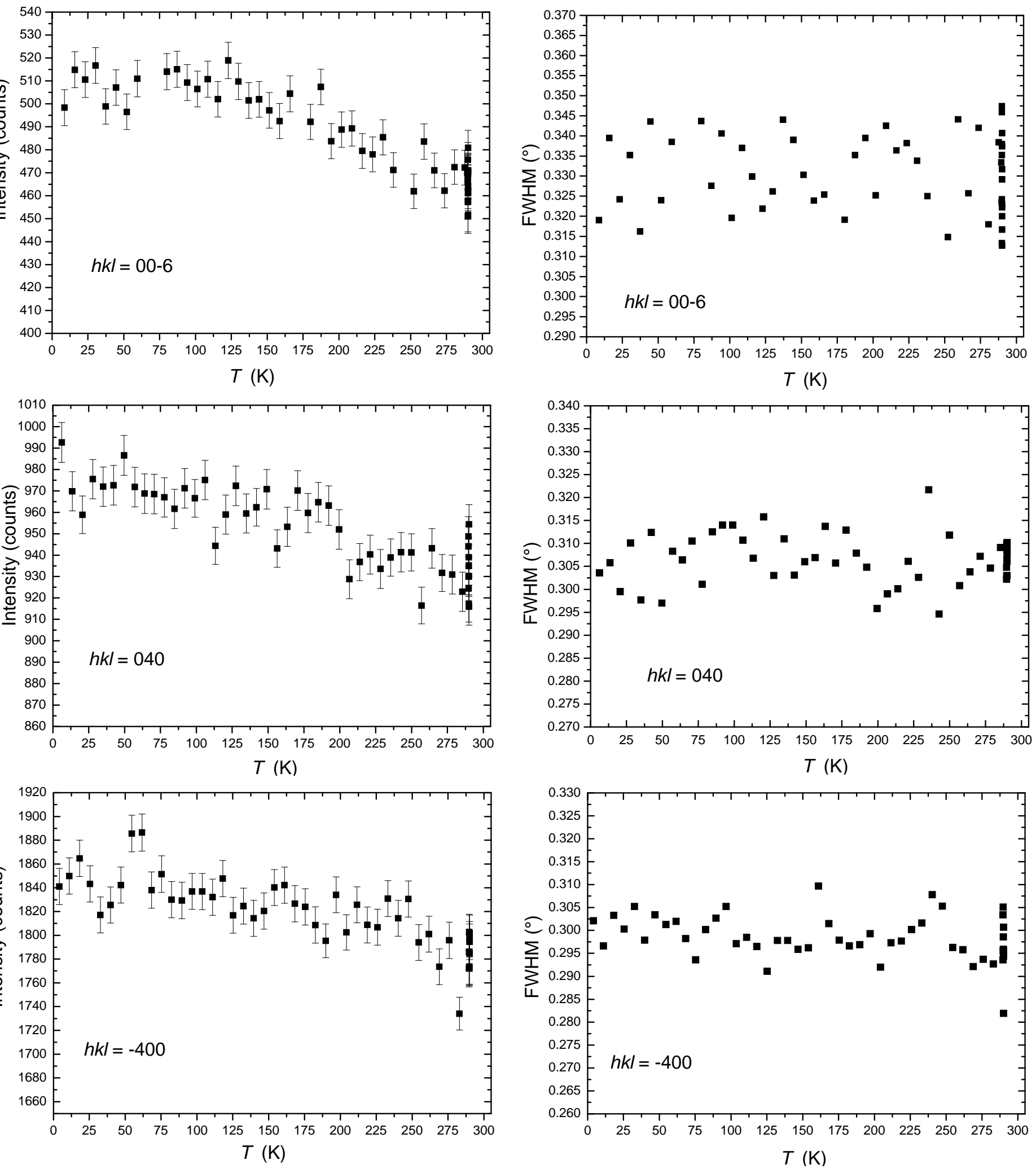
Figure 3. Difference-Fourier maps of the nuclear density ( $x y$ sections, $x$ horizontal; $z \sim 0.7$ ) at $298 \mathrm{~K}$ (top) and at $3 \mathrm{~K}$ (down), calculated with coefficients $F O-F C$ and phased by $F c$. The FC were calculated from a structural model without the $\mathrm{H}$ site. Color bar unit: $\mathrm{fm} / \AA^{3}$.
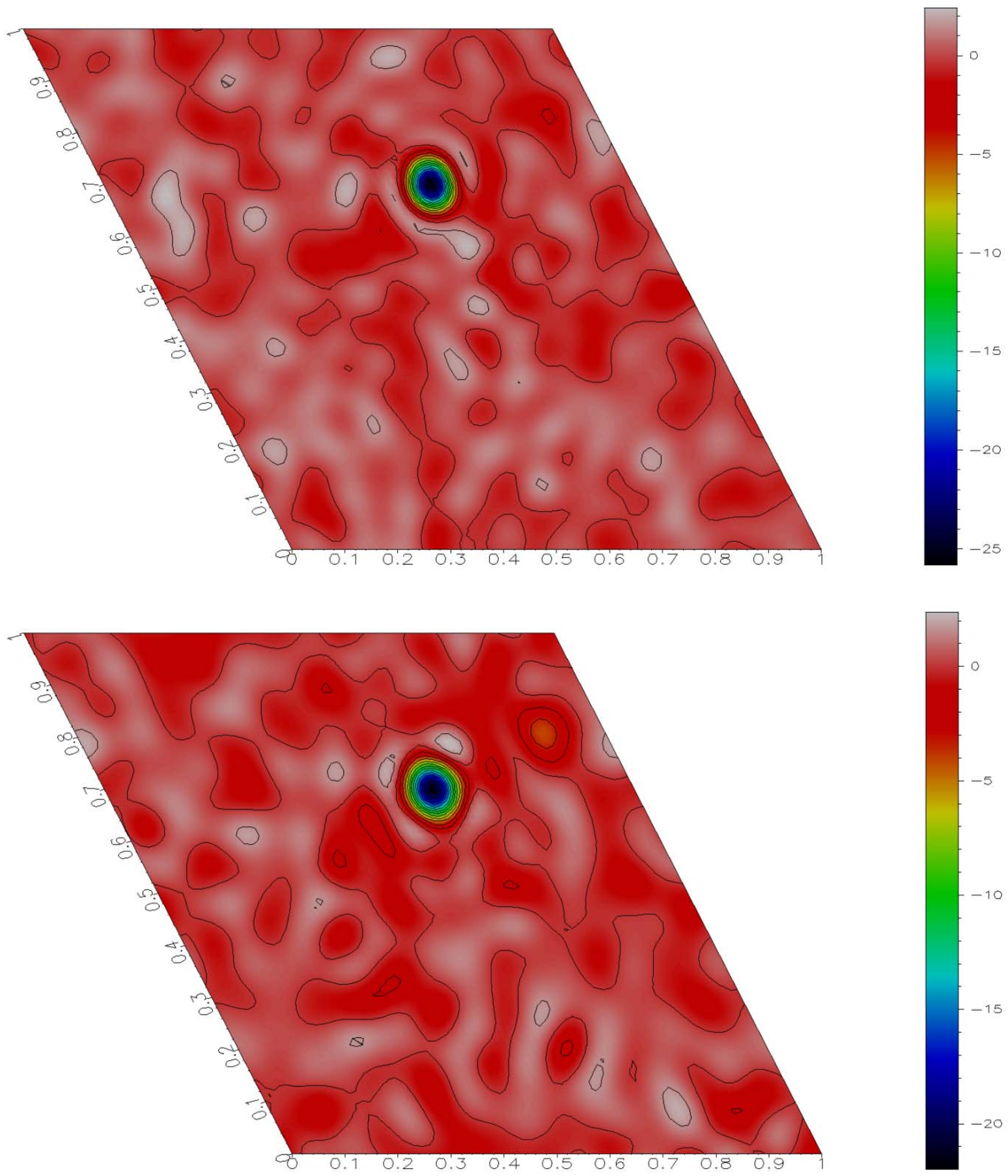


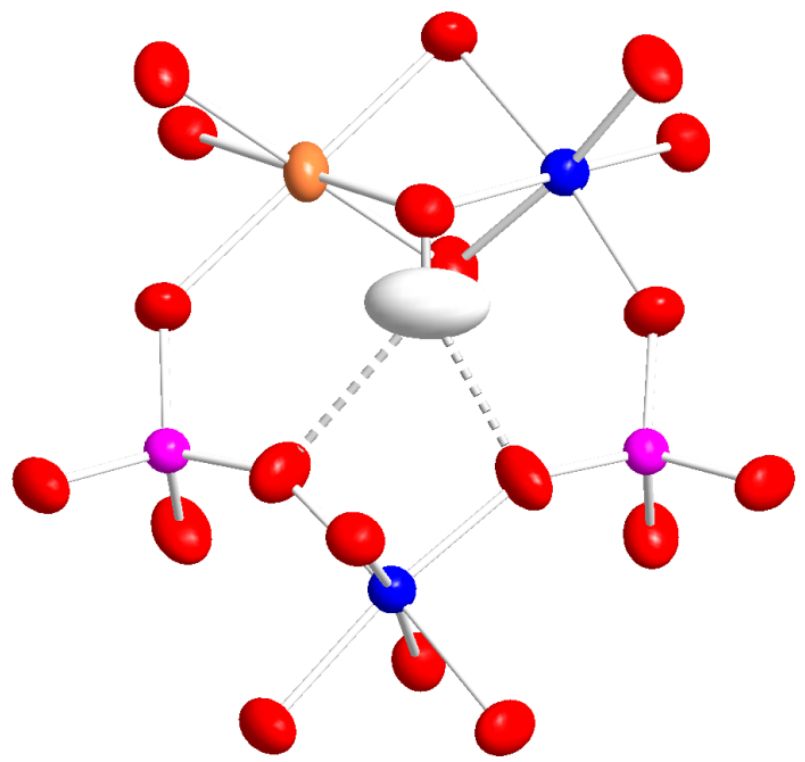

Figure 4. Magnitude of the atomic displacement ellipsoids, with probability factor $99 \%$, based on the structure refinements at $298 \mathrm{~K}$ (left side) and at $3 \mathrm{~K}$ (right side). Colors and orientations as in Fig. 1. 